\title{
ELECTRIC AND ELECTROCHEMICAL PROPERTIES OF CATALYTICALLY ACTIVE OXYGEN ELECTRODE MATERIALS
}

\section{A.J. BURGGRAAF, M.P. VAN DIJK and K.J. DE VRIES}

Twente University of Technology, Department of Chemical Engineering, Laboratory for Inorganic Chemistry, Materials Science and Catalysis, P.0. Box 217, 7500 AE Enschede, The Netherlands

The electrical conductivity has been investigated of some oxygen ion and mixed conducting materials. Electrodes are prepared from thin sputtered layers of these oxides combined with a small Au or Pt strip. The kinetics of the oxygen reaction has been studied for temperatures of $820-1020 \mathrm{~K}$ and $\mathrm{P}_{\mathrm{O}_{2}}$ values of $10^{-4}-1$ atm. respectively.

Highest oxygen ion conductivities are found in solid solutions of $0.7 \mathrm{Bi}_{2} \mathrm{O}_{3}-0.3 \mathrm{~Tb}_{2} \mathrm{O}_{3} \mathrm{~F}$ followed by $0,7 \mathrm{CeO}_{2}-0.3 \mathrm{~Tb}_{2} \mathrm{O}_{3}(\mathrm{CT}-30)$ and $\left(\mathrm{Tb}_{\mathrm{X}} \mathrm{Gd}_{1-\mathrm{x}}\right)_{2} \mathrm{Zr}_{2} \mathrm{O}_{7}$ with pyrochlore structure and $\left.\mathrm{x}=0.9 \mathrm{TGZ}-0\right)$. Highest, p-type, electronic conductivities are found in CT-30 and TGZ with $x=1$. TGZ-0 was used in all experiments as the solid electrolyte.

Combined current-overvoltage $(\eta)$ and impedance measurements show that with Au strips the nature of the oxidic materials has a pronounced effect on especially the cathodic polarization, the effect being larger with larger $\eta$. Introduction of p-type conductivity does not decrease the electrode resistance. The Butler-Volmer equation is obeyed with effective cathodic and anodic transfer coefficients close to 0.5 and 1.5 respectively while the effective exchange current varies as the 0.5 power of $\mathrm{P}_{\mathrm{O}_{2}}$. These results can be interpreted by a mechanism where charge transfer in the metaloxide region is rate controlled by surface diffusion on the oxide.

\section{INTRODUCTION}

Slow electrochemical reactions reduce the efficiency of fuel cells, steam electrolysers and oxygen pumps $1-5 / 17$ and complicate the response of gas sensors at low temperature $6 / 7 / 10$. For redox reactions in the gasphase both metals and oxides have been tested as electrode materials applied on top of an oxygen ionconducting electrolyte which is in most cases a solid solution of $\mathrm{InO}_{2}-\mathrm{Y}_{2} \mathrm{O}_{3}{ }^{2 / 5 / 8 / 12}$. It has been shown that both the nature of the surface of the oxidic electrolyte/electrode and of the electrode metal play an important role especially at high temperatures 2/5/8-12. Reaction mechanisms and rate controlling steps are dependent on temperature, partial pressure of oxygen and other reactants and on electrode morphology in addition to the expected dependence on material properties.

As has been discussed oxygen vacancies $8 / 13-16$ the occurence of electronic conductivity $9 / 10 / 18$ and the presence of (catalytically) active sites $^{3 / 12-19}$ most probably play an important role. Oxide layers with mixed conductivity and catalytically active centers may therefore improve the behaviour of metal electrodes or even replace them and they are especially interesting for highly selective electrodes in gas sensors and electrochemical or - catalytical redox reactions (e.g. methanol oxidation, NO reduction $13-20 / 22)$. For these reasons they are investigated in our laboratory. $\mathrm{Gd}_{2} \mathrm{Zr}_{2} \mathrm{O}_{7}$ (इTGZ-C) was selected in this study as an alternative electrolyte material with good ionic conductiv$i$ ty 20 and interesting properties. The structure consist of pyrochlore domains in a fluorite matrix. The degree of order can be varied and the boundaries between domains and matrix have a defect chemistry giving rise to rapid oxygen diffusion path ways ${ }^{21}$. Preliminary experiments with the TGZ system indicate that the CO oxidation rate at $450^{\circ} \mathrm{C}\left(r_{450}\right)$ is dependent on the degree of order and that high values can be obtained $23 / 24$. This points to active sites which nature depend on ordering degree. oxidic electrode materials are investigated in the form of thin layers applied on top of the electrolyte. The system $\left(T b_{x} G d d_{1-x}\right)^{Z} Z r_{2} O_{7}(\equiv T G Z-x)$ was investi- 
gated because Tb introduces electronic conductivity in the pure ionically conducting system for $x=0$ and is reported to be active in high

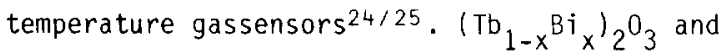
( $\left.\mathrm{Tb}_{1-\mathrm{x}} \mathrm{Ce}_{\mathrm{x}}\right)_{2+\mathrm{y}} \mathrm{called}$ further $\mathrm{BT}$ and CT respectively were studied because they have a different defect chemistry, and are expected to have higher conductivities, while $\mathrm{CeO}_{2}$ is an active oxidation catalyst. The present paper concentrates on TGZ with $x=0$ and $1(\equiv T G Z-100)$ and on CT-30 ( $x=0.3)$.

\section{EXPERIMENTAL}

A full description of experimental methods is given elsewhere ${ }^{24}$. The most important features are summarized below. Electrode layers of TGZ-0, TGZ-100 or CT-30 with a thickness of 150 or 600 $\mathrm{nm}$ are applied on TGZ-0 ceramic substrates by radiofrequent sputtering at $1-1.5 \mathrm{kV}$ in an atmosphere of $82 \%$ Ar and $18 \% \mathrm{O}_{2}$ at 0.6-0.8 $\mathrm{Pa}$. The metal composition was found to deviate less than $1 \%$ from the target composition ( $X$-ray fluorescence). The macrostructure of the layers was examined by $X$-ray diffraction and S.E.M. Current-overvoltage measurements were performed potentiostatically in a three electrode cell. The potential was raised linearly with a rate of $4 \mathrm{mv} \mathrm{sec}^{-1}$. The counter electrode consisted of a $225 \mathrm{~nm}$ thick sputtered porous Pt 1ayer. The reference electrode on the other side of the electrolyte consisted of a spring loaded $\mathrm{Pt}$ point contact. The working electrode consisted of a ring of the sputtered oxide electrode with an outer diameter equal to that of the electrolyte disk $(10 \mathrm{~mm})$ and an inner diameter of $5 \mathrm{~mm}$. Electrical contact was made by a spring loaded annular strip of $\mathrm{Au}$ (or in some cases $\mathrm{Pt}$ ) with a geometric contact surface of $15 \pm 3 \mathrm{~mm}^{2}$ and a width of $0.6 \pm 0.1 \mathrm{~mm}$. From an combination of conductivity and capacity measurements it was concluded that the real contact surface is at least a factor 10 smaller. Thermovoltaic effects were not present. The overvoltage measurements were corrected by AC impedance analysis ${ }^{24}$ for the fact that working and reference electrode do not feel the same equipotential plane.

\section{RESULTS}

Conductivities as a function of temperature are given in figure 1 . The highest ionic conduc-

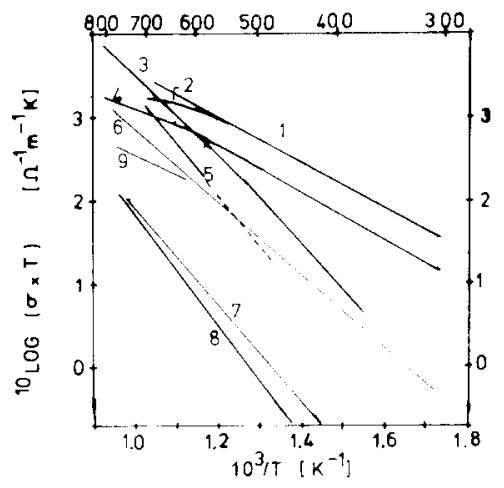

FIGURE 1

Electronic and ionic conductivities of investigated oxides at $\mathrm{P}_{\mathrm{O}_{2}}=0.21 \mathrm{~atm}$.

1.CT-30 (total) 2.CT-30 (electr.) 3.BT-30(ECG-30 ionic) 4.TGZ-100 (total, electr.) 5.CT-30 (ionic) 6.TGZ-0 (pyr.) 7.TGZ-0 (flu.) 8.TGZ-100 (ionic) 9. BT-30 (electr.).

tivities $\sigma_{i}$ are found in BT-30 ( $\left.x=0.7\right)$ and CG 30 followed by CT-30 and $\mathrm{Gd}_{2} \mathrm{Zr}_{2} \mathrm{O}_{7}$ (TGZ) with pyrochlorephase, TGZ-0 with fluorite phase and TGZ100 ( $\equiv \mathrm{Tb}_{2} \mathrm{Zr}_{2} \mathrm{O}_{7+y}$ ) have considerably lower ionic conductivities. The electronic conductivity is in all cases predominantly $p$ type. Activation energies $E_{i}$ for ionic conductivity are in order of decreasing $E_{j}$ values (given in parenthesis in kJmole $\left.e^{-1}\right)$ : TGZ-100 (126), CT-30 and TGZ-0 with fluorite structure $(\approx 113)$, TGZ-0 with pyrochlore structure and $\mathrm{BT}-30 \quad(\approx 87)$. Activation energies for electronic conductivity are about equal for CT-30 and TGZ-100 (52-60) followed by BT-30( $\approx 40)$. For the TGZ system it has been proven that 
the electron hole conductivity is due to a small polaron mechanism in the Tb sublattice with mobilities of $10^{-10}-10^{-8} \mathrm{~m}^{2}(\mathrm{Vs})^{-1}$ at $970 \mathrm{~K}$ depending on the $\mathrm{Tb}$ concentration ${ }^{26}$. The $\mathrm{Tb}^{4+} /$ $\mathrm{Tb}^{3+}$ ratio hardly depends on composition and reaches a maximum value of 0.25 at $\mathrm{P}_{\mathrm{O}_{2}}=1 \mathrm{~atm}$. The sputtered layers have a small porosity (SEM observation) but are rather strongly textured with $\{100\}$ crystal planes oriented parallel to the surface. After heat treatment sharpened $X$-ray diffraction 1 ines indicate a good crystallinity (fluorite structure). Typical current(i) - overvoltage (y) curves for TGZ-0/100 and CT-30 are given in fig.2. In all configurations anodic

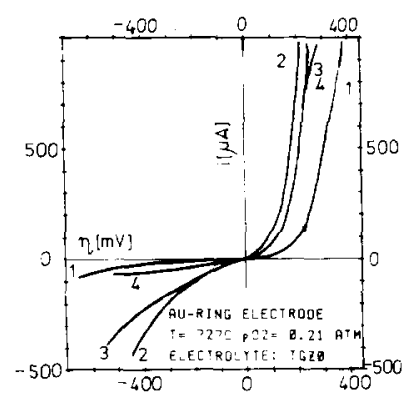

FIGURE 2

Polarization curves for oxides with Au strip contacts at $727^{\circ} \mathrm{C}$ and $\mathrm{P}_{0_{2}}=0.21 \mathrm{~atm}$ on TGZ-0. 1. uncovered electrolyte, $2.600 \mathrm{~nm}$ sputtered TGZ-0 $3.600 \mathrm{~nm}$ sputtered CT-30,4.150nm sputt. TGZ-100

currents are much larger then cathodic ones and so cathodic polarization is more severe. With Au contact strips polarization is largest for the uncovered electrolyte $(T G Z-0)$. A decrease in polarization is obtained with a sputtered layer of the same material (TGZ-0), a smaller decrease with CT-30 layers. At $\eta=500 \mathrm{mV}, i-v a l u e s$ are increased by factors of about 11 and 6 respectively. No improvement is achieved with TGZ-100 layers. Obviousiy introduction of Tb in TGZ-O layers increases the (cathodic) polarization. The results can be analyzed by means of a
Butler Volmer equation [1] in which diffusion phenomena are incorporated and which can be reduced to equation [2].

$$
i=\frac{\exp \left(\alpha_{a} \eta^{\star}\right)-\exp \left(-\alpha_{c} \eta^{\star}\right)}{i_{0}^{-1}+i_{\ell a}^{-1} \exp \left(\alpha \eta^{\star}\right)+i_{\ell e^{-1} \exp \left(-\alpha_{c} \eta^{\star}\right)}}
$$

with $\eta^{\star}=\eta F / R$ and index $\ell$ indicating a limiting current.

The behaviour at not too large $\eta$ values is

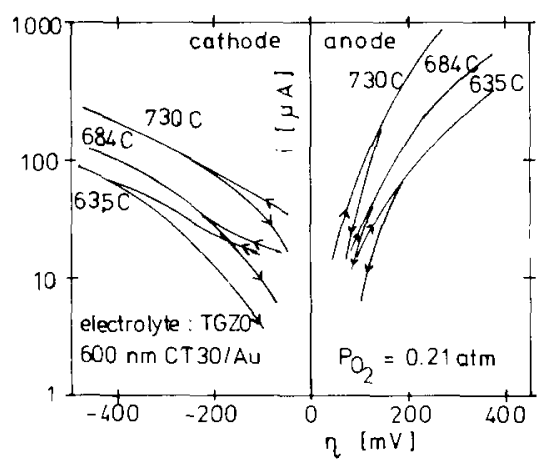

FIGURE 3.

Typical plot of $\log i$ vs $n$ for a CT-30 layer $(600 \mathrm{~nm})$ with $\mathrm{Au}$ strip at $\mathrm{P}_{\mathrm{O}_{2}}=0.21 \mathrm{~atm}$.

represented by Tafel plots (Fig.3) from which $\mathbf{i}_{0}$ can be deduced and by the electrode resistance $R_{e l}$ as determined from AC impedance measurement ${ }^{24}$. $R_{e l}$ and $i_{0}$ are interrelated by $R_{e l}=$ $(\eta / i)_{n \rightarrow 0}=R T /\left[\left(\alpha_{a}+\alpha_{c}\right) F i_{0}\right]$. Results are presented in figure 4 and table 1 . The behaviour of the sputtered layers as characterized by $R_{e l}$ follows the same sequence as given above for 1 arger $\eta$ values but with smaller differences. For the higher temperatures charge transfer coefficients amount $\alpha_{c} \approx 0.5$ and $\alpha_{a} \approx 1.5$. Temperature decrease results in a decrease of $\alpha_{a}$ and an increase of $\alpha_{c}$. Activation enthalpies of $R_{e l}$ are about 100 kJmole $e^{-1}$ for all oxide-Au configurations except for CT-30 at the higher temperatures. The $i-\eta$ curves can be fitted with equation [2]. 
TABLE 1.

Transfer coefficients $\alpha$ and activation enthalpies $\Delta H$ of the electrode resistance $R_{e l}$. Numbers in the $\alpha$ colums indicate low and high temperature limits respectively. $P_{0_{2}}=0.21$ atm except for marks 1 and 2 with $P_{0}=0.01$ and 0.43 atm. Thickness of sputtered layers is $600 \mathrm{~nm}$ except mark 3 (with $150 \mathrm{~nm}$ )

\begin{tabular}{|c|c|c|c|c|}
\hline \multicolumn{2}{|c|}{$\begin{array}{l}\text { Electrode } \\
\text { configuration }\end{array}$} & $\begin{array}{l}\alpha \\
{ }_{a} \\
\pm 0.2\end{array}$ & $\begin{array}{l}{ }^{\alpha}{ }_{c} \\
\pm 0.2\end{array}$ & $\begin{array}{c}\Delta \mathrm{H} \\
\mathrm{kJmol}\end{array}$ \\
\hline \multicolumn{2}{|c|}{ bareTGZ0/Au } & 1.6 & 0.35 & 120 \\
\hline $\mathrm{TGZO} / \mathrm{Au}$ & 1 & $1.4-1.7$ & $0.8-0.6$ & 101 \\
\hline $\mathrm{TGZO} / \mathrm{Au}$ & & $1.1-1.6$ & $0.7-0.6$ & 106 \\
\hline $\mathrm{TGZO} / \mathrm{Au}$ & 2 & 1.5 & 0.6 & 110 \\
\hline TGZO/Pt & & 1.1 & 0.7 & $240-140$ \\
\hline $\mathrm{CT} 30 / \mathrm{Au}$ & 3 & $1.3-1.5$ & $0.6-0.5$ & $100-150$ \\
\hline CT30/Au & & $1.3-1.5$ & $0.7-0.4$ & $100-150$ \\
\hline CT30/Pt & & 1.1 & 0.7 & $240-140$ \\
\hline $\mathrm{TGZO} / \mathrm{Au}$ & 3 & $1.2-1.5$ & $0.4-0.5$ & 99 \\
\hline
\end{tabular}

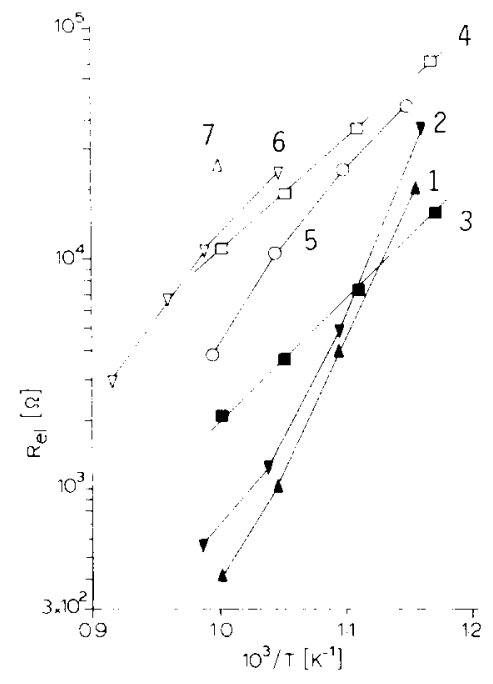

FIGURE 4

Scaled total electrode resistance $R_{e l}$ of several oxide layer metal combinations.

$1=\mathrm{CT}-30 / \mathrm{Pt}, \quad 2=\mathrm{TGZ}-0 / \mathrm{Pt}, \quad 3=\mathrm{TGZ}-0 / \mathrm{Au}$, $4=\mathrm{TGZ}-100 / \mathrm{Au}, 5=\mathrm{CT}-30 / \mathrm{Au}, 6=\mathrm{CT}-30 / \mathrm{Au}$, 7 =uncovered TGZ-0/Au. Ali layers are $600 \mathrm{~nm}$ thick except 4 and $6(150 \mathrm{~nm})$.
Important conclusions can be drawn at this moment. Introduction of $p$ type conductivity increases the electrode resistance and polarization. Furthermore the character of the oxidic electrode matrix has an important effect when Au strips are used. With $\mathrm{Pt}$ strips and in air $\mathrm{R}_{\mathrm{el}}$ values are independent of the oxidic material (Table 1 and Figure 4) so in this case the electrode behaviour is determined mainly by the metal. Comparing Au and Pt on CT-30 (figure 5) we observe that at 1 arger $\eta$ values $(\approx 400 \mathrm{mv})$ the

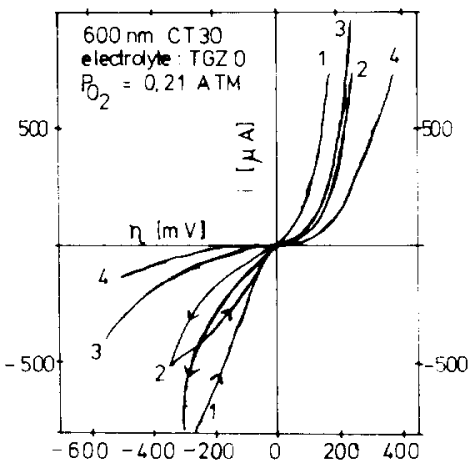

FIGURE 5 .

Anodic and cathodic polarization curves for CT-30 layers with Pt or Au strip contacts at $P_{\mathrm{O}_{2}}=0.21 \mathrm{~atm}$

1 and 2: Pt electrode, 728 and $684^{\circ} \mathrm{C}$ resp. 3 and 4: Au electrode, 728 and $684^{\circ} \mathrm{C}$ resp.

the currents are larger for Pt with a factor of about 3-10 depending on the temperature. For $\mathrm{T}<600^{\circ} \mathrm{C}$ and in air Au strip electrodes however have a smaller electrode resistance than $\mathrm{Pt}$.

Finally the effect of $\mathrm{P}_{\mathrm{O}_{2}}$ can be represented by $\mathrm{R}_{\mathrm{el}} \mathrm{1}^{\alpha} \mathrm{P}_{\mathrm{O}_{2}}^{\mathrm{m}}$ with $\mathrm{m} \approx-0.47$ for all oxides with $\mathrm{Au}$ strips and for $\mathrm{P}_{\mathrm{O}_{2}}=10^{-5}-1 \mathrm{~atm}$. If we remind that $\alpha$ and $m$ are interrelated $11 / 12$ and that $\alpha_{a} \approx 1.5$ and $\alpha_{c} \approx 0.5$ further analysis $19 / 24$ leads to the conclusion that there is only one mechanism being able to reproduce these combination of $\alpha$ and $m$ values. This is a charge transfer process with 
$\alpha_{\mathrm{a}}=\alpha_{\mathrm{c}}=1$ were both anodic and cathodic polarization are rate controlled by a diffusion process from an adsorption site to an electrochemical reaction site probably on the oxide surface. A full discussion is given elsewhere11/19/24, some arguments are given below.

If we define a ratio $Q=\left(i_{0} L^{2} / 2 \widetilde{D} C_{0}\right)^{1 / 2}$ then $Q$ is a measure of the ratio of the charge transfer process (with $\alpha_{a}=\alpha_{c}=1$ ) and of the rate of a diffusion process with (chemical) diffusion coefficient $\widetilde{D}$ from adsorption site $(a, s)$ to reaction site $(r, s)$ separated by a distance $L$ and with an oxygen concentration on the adsorption site $\mathrm{C}=\mathrm{C}_{0}{ }^{11}$.

For diffusion limitation we have $Q<<1$ and eq. 1 (with $\alpha_{a}=\alpha_{c}=1$ ) reduces to

$$
i=i_{0, a p p}\left[\exp (1.5 \eta) \star-\exp \left(-0.5 \eta^{\star}\right)\right]
$$

with $i_{0 \text {,app }}$ is a function of $\left(i_{0} / Q\right)$. In this case the boundary condition is that the oxygen concentration on the reaction site $C_{r} \ll C_{0}$ but that the concentration on the adsorption site $C_{\text {ad }}=C_{0}$ (which implies that a limiting current plateau is not yet reached).

Calculation by Nyuyen and a ${ }^{19}$ yield an explicit function for $i_{0, \text { app }}$ which gives $m=-1 / 2$. For $Q \approx 1$ values of $\alpha_{a}$ and $\alpha_{c}$ must be intermediate between their limiting values. This obviously happens in our experiments when the temperature is lowered. The above mentioned set of parameters is consistent with an overall reaction:

$$
0_{r, s}+v_{0}^{*}+2 e=0_{0}+v_{r, s}
$$

with $V$ is a vacant site

A tentative reaction sequence might be

$$
\begin{array}{rlrl}
0_{2}(g)+v_{\text {ad }}(c)+e^{\prime} & =0 \\
0_{2, a d}^{\prime}+v_{r, s}(c) & {[4 a]} \\
0_{2}^{\prime}(c)+v_{r, s}(c)+e & =20^{\prime}(c) & 0_{2}^{\prime}(c)+v_{a d}(c) & {[4 b]} \\
2\left[0^{\prime}(c)+v_{o}{ }^{o o}(c)+e\right. & \left.=0_{0}^{\circ}+v_{r, s}(c)\right] & {[4 d]}
\end{array}
$$

with (C) indicating that the proces proceeds on the oxidic surface. Steps $4 \mathrm{~b}$ and $4 \mathrm{~d}$ are the steps where respectively limitation by diffusion or by charge transfer occurs. Reaction 4 yields values of $\beta=1 / 2, r=0, \gamma_{a}=\gamma_{c}=2$ and $v=2$. With $\alpha_{c}=$ $\gamma_{c} / \nu+r \times \beta$ and $\alpha_{a}=\left(\gamma_{a} / \nu+r-r \times \beta\right)^{12 / 19 / 24}$ this results in $\alpha_{a}=\alpha_{c}=1$ which was required by the model.

\section{REFERENCES}

1. E.C. Subbarao and H.S. Maiti, Solid State Ionics 11 (1984) 317

2. M.J. Verkerk, M.W.J. Hammink and A.J. Burggraaf, J. Electrochem. Soc. 130 (1983) 70 .

3. J.J. Olmer, J.C. Vigue and E.J.L. Schouler, Solid State Ionics 7 (1982) 23

4. F.J. Rohr, in: Solid Electrolytes eds. P. Hagenmuller and W. Van Gool (Academic Press, New York 1978) p.431.

5. H.S. Isaacs and L.J. 01mer, J. Electrochem. 982) 436 .

6. A.J.A. Winnubst, A.H.A. Scharenborg and A.J. Burggraaf, J. Appl. Electrochem. 15 (1985) 139.

7. P. MC Geehin and D.E. Williams in Ceramics in advanced energy technologies, eds. H. Krockel, M.Meiz and O. v.d. Biest, (D.Reidel Publ. Cie, Dordrecht 1984) p.422.

8. E.J.L. Schouler, Solid State Ionics $9 \& 10$ (1983) 945.

9. E.P. Wirtz, H.S. Isaacs, Solid State Ionics $9 \& 10$ (1983) 963.

10. S.P.S. Badwal, M.J. Bannister and M.J. Murray, J. Electrochem. Soc. 168 (1984) 963.

11. D.Y. Wang and A.S. Nowick, J. Electrochem. Soc. 178 (1981) 55 .

12. A.J.A. Winnubst, A.H.A. Scharenborg and A.J. Burggraaf, Solid State Ionics 14 (1984) 319 .

13. M. Stoukides and C.G. Vayenas, J. Electrochem. Soc. 131 (1984) 839.

14. T.M. Gur, R.A., Huggins Science 219 (1983) 217.

15. B.G. Ong, C.C. Chiang and D.M. Mason, Solid State Ionics $3 / 4$ (1981) 447 . 
16. S. Pancharatnam, R.A. Huggins and D.M. Mason, J. Electrochem. Soc., 122 (1975) 869.

17. G.B. Barbi and C.M. Mari, Solid State Ionics 6 (1982) 341 .

18. B.C. Nguyen and D.M. Mason subm. J. Electrochem. Soc.

19. B.C. Nguyen, L.M. Rincon Rubio and D.M. Mason, ibid.

20. M.P. van Dijk, K.J. de Vries and A.J. Burggraaf, Solid State Ionics $9 / 10$ (1983) 9 .

21. M.P. van Dijk, F.C. Mylhof and A.J. Burggraaf, J. Sol. State Chem. 1985 subm.
22. M.P. van Dijk, J.H.H. ter Maat, P.J. Gellings and A.J. Burggraaf, Mat. Res. Bul1. 19 (1984) 149.

23. J.H.H. ter Maat, M.P. van Dijk, P.J. Gellings and A.J. Burggraaf, ibid 1271 .

24. M.P. van Dijk Ph.D. Thesis Twente University of Technology, Enschede, The Netherlands, Sept. 1985.

25. G.B. Barbi, A. Casiraghi and C.M. Mari, Rev. SC. Instr. 54 (1983) 486.

26. M.P. van Dijk, K.J. de Vries and A.J. Burggraaf, Solid State Ionics 1985, in print. 